\title{
Waking up in pain: an infographic
}

\author{
Eric S Schwenk (i) , \\ Rajnish K Gupta (1) ${ }^{2}$
}

\section{SUMMARY}

In this prospective cohort study Rasmussen and colleagues ${ }^{1}$ reported their findings of 3,702 patients who underwent a variety of surgeries and found that $20 \%$ of patients reported moderate or severe pain immediately following surgery until 15 minutes after post-anesthesia care unit arrival. The study included 31 public hospitals in Denmark, Greenland, and the Faroe Islands over a 5-day period. Risk factors for higher pain levels included female sex, younger age, preoperative pain, daily opioid use, and major surgical procedures. The authors found postoperative nausea and vomiting occurred in only 5\% of cases with female sex again being identified as a risk factor, consistent with prior studies. Finally, a greater proportion of patients who were sedated in the operating room had pain in the post-anesthesia care unit versus nonsedated patients (11 versus $8 \%$; $\mathrm{p}=0.008)$. This study illustrates that early control of postoperative pain remains a challenge.

${ }^{1}$ Anesthesiology, Sidney Kimmel Medical College at Thomas Jefferson University, Philadelphia, Pennsylvania, USA

${ }^{2}$ Anesthesiology, Vanderbilt University Medical Center, Nashville, Tennessee, USA

Correspondence to Eric S Schwenk, Anesthesiology, Sidney Kimmel Medical College at Thomas Jefferson University, Philadelphia, Pennsylvania, USA; prepdrum@gmail.com

\section{Waking Up in Pain After Surgery}

Results of a prospective cohort study

of 31 public hospitals in Denmark, Greenland, and Faroe Islands over 5 days (total of 3,675 surgical procedures)

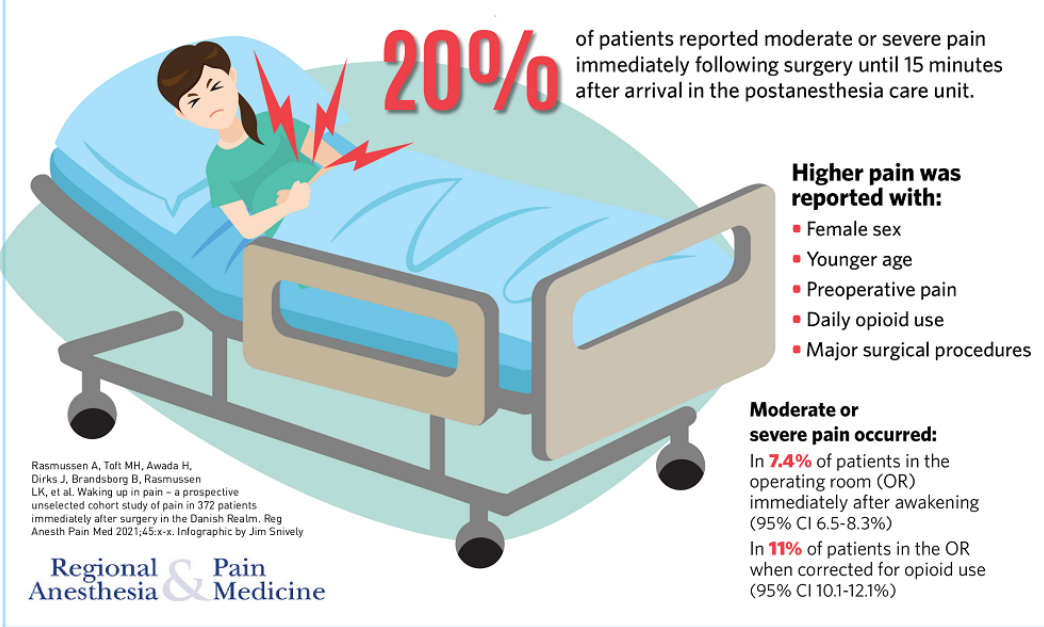

Twitter Eric S Schwenk @ESchwenkMD and Rajnish K Gupta @dr_rajgupta

Acknowledgements We would like to acknowledge Jim Snively, artist, of Pittsburgh, PA, for creation of this infographic.

Contributors ESS created the summary and designed the concept for the infographic. RKG edited and approved the final manuscript.

Funding The authors have not declared a specific grant for this research from any funding agency in the public, commercial or not-for-profit sectors.

Competing interests None declared.

Patient consent for publication Not required.

Provenance and peer review Commissioned; internally peer reviewed.

(C) American Society of Regional Anesthesia \& Pain Medicine 2021. No commercial re-use. See rights and permissions. Published by BMJ.

\section{Check for updates}

To cite Schwenk ES, Gupta RK. Reg Anesth Pain Med 2021;46:947.

Received 25 July 2021

Accepted 27 July 2021

Published Online First 18 August 2021

\section{S Linked}

- http://dx.doi.org/10.1136/rapm-2021-102583

Reg Anesth Pain Med 2021;46:947.

doi:10.1136/rapm-2021-103009

\section{ORCID iDs}

Eric S Schwenk http://orcid.org/0000-0003-3464-4149 Rajnish K Gupta http://orcid.org/0000-0003-34014737

\section{REFERENCE}

1 Rasmussen A, Toft MH, Awada HN, et al. Waking up in pain - a prospective unselected cohort study of pain in 3702 patients immediately after surgery in the Danish realm. Reg Anesth Pain Med 2021;46:948-53. 